\title{
Heart infarct as the major cause of death of hematological patients as identified by autopsy
}

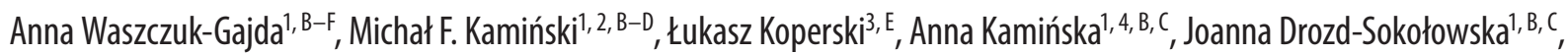 \\ Zbigniew Lewandowski ${ }^{6, C}$, Aleksander Wasiutyński, ${ }^{5, F}$, Barbara Górnicka ${ }^{3, F}$, Wiesław W. Jędrzejczak ${ }^{1}$, A, E, F \\ ${ }^{1}$ Department of Hematology, Oncology and Internal Diseases, Medical University of Warsaw, Poland \\ 2 Department of Gastroenterology, Hepatology and Oncology, Medical Centre for Postgraduate Education, The Maria Skłodowska-Curie Memorial Cancer Centre and Institute \\ of Oncology, Warszawa, Poland \\ ${ }^{3}$ Department of Pathology, Medical University of Warsaw, Poland \\ ${ }^{4}$ II Department of Obstetrics and Gynecology, Medical University of Warsaw, Poland \\ ${ }^{5}$ Department of Pathomorphology, National Institute of Geriatrics, Rheumatology and Rehabilitation, Warszawa, Poland \\ ${ }^{6}$ Department of Epidemiology and Biostatistics, Medical University of Warsaw, Poland \\ A - research concept and design; $B$ - collection and/or assembly of data; $C$ - data analysis and interpretation; \\ $\mathrm{D}$ - writing the article; $\mathrm{E}$ - critical revision of the article; $\mathrm{F}$ - final approval of the article
}

Address for correspondence

Anna Waszczuk-Gajda

E-mail: annawaszczukgajda@gmail.com

\section{Funding sources}

The study was supported by the Statutory Funds provided by the Polish Ministry of Science and Higher Education to the Department of Hematology, Oncology and Internal Diseases, Medical University of Warsaw, Poland.

Conflict of interest None declared

Received on April 4, 2016 Reviewed on June 25, 2016 Accepted on 0ctober 17, 2016

D0I

$10.17219 /$ acem $/ 65866$

Copyright

Copyright by Author(s)

This is an article distributed under the terms of the

Creative Commons Attribution Non-Commercial License

(http://creativecommons.org/licenses/by-nc-nd/4.0/)

\section{Abstract}

Background. Despite progress in diagnostic procedures, clinical diagnosis is not always confirmed by an autopsy. An autopsy is a valuable tool in evaluating diagnostic accuracy.

Objectives. The aim of the study was to compare clinical diagnoses of immediate causes of death with autopsy findings in patients with hematological malignancies or aplastic anemia.

Material and methods. In this study, the results of 154 autopsies (1993-2004) of patients with hematological diseases were reviewed and compared with clinical data. The most probable causes of death in the case of particular hematological diseases as well as the discordances between clinical and autopsy diagnoses and their relation to the clinical characteristic were identified in the studied cohort, which primarily included patients whose death at that particular time was not explained by the clinical course, and in 50\% of cases was sudden.

Results. Although various combined infections have been found to be responsible for the largest number of deaths (26.6\%), the most common single cause was myocardial infarction (29 patients, 18.8\%). The discordance between clinical and post-mortem diagnoses of immediate causes of death was found in 55 patients (35.7\%; 95\% Cl 28.2-42.8\%), with 50.9\% of cases considered class I discrepancies according to Goldman's criteria. The myocardial infarction was found to be clinically undiagnosed in 69\% of cases. In $41 \%$ of cases, it was a class I discrepant diagnosis.

Conclusions. This data suggests that hematological patients require special attention and probably preventive measures concerning coronary heart disease, particularly during the initiation of antineoplastic therapy.

Key words: hematology, malignancies, cause of death, discordance, autopsy 


\section{Introduction}

In the past few decades, great progress has been made in the management of hematological malignancies. However, the mortality rates in these diseases are still high and the immediate causes of death are not always clear when only clinical data is taken into consideration. It is essential to elucidate the precise causes of mortality in hematological malignancies and aplastic anemia in order to properly focus the research efforts and to improve the management and treatment.

Previous studies in different medical specialties have shown that clinical diagnoses of causes of death are characterized by a high discordance rate (0-29\%) with autopsy findings. ${ }^{1-6}$ It could be even higher in specific groups with particularly severe or rare diseases, e.g., in cancer patients. ${ }^{1,7,8}$ This suggests the post-mortem examination to be the best tool to verify the clinical diagnosis. ${ }^{9-12}$

In this study, we have compared clinically made diagnoses of immediate causes of death with autopsy findings in 154 patients with hematological malignancies or aplastic anemia. We intended to identify the most probable causes of death in different hematological diseases, the most frequently missed diagnoses and the discordance rate between clinical and anatomopathological investigation.

\section{Material and methods}

\section{Patients}

The study was performed in the Department of Hematology, Oncology and Internal Diseases at Medical University of Warsaw, Poland. After reviewing the reports of 1,179 cases of patients who died in the years 1993-2004 in this Department, it was found that 181 autopsies (15.6\%) were performed, and from that group 27 cases (14.9\%) were excluded because of incomplete records of either the clinical course of disease ( 2 cases), autopsy (23 cases) or both ( 2 cases). The remaining 154 cases (13.1\% of all deaths) composed the study population, which was characterized by a median age of 50.9 years $( \pm 17.1)$, even sex distribution - 77 males (50\%) and 77 females (50\%), and clinical diagnosis and the stage of the disease as shown in Table 1.

The distribution of primary hematological diseases in the entire reviewed group of 1,179 cases is displayed in Table 1, together with the distribution of diagnoses in patients who underwent an autopsy examination.

\section{Autopsy}

Patients were selected for the autopsy in this Department on the basis of relatively uniform criteria, defined as follows:

- any death within $24 \mathrm{~h}$ of admission;

- death unexplained by the clinical situation of the patient, including sudden death;
- death while participating in a clinical trial;

- death after any form of hematopoietic stem cell transplantation.

For the purpose of this study, patients were categorized into early or advanced primary disease at the time of death. Early disease, for the purpose of this study, is the disease that should not be by itself an immediate cause of death and involves a patient who still has available treatment options. Advanced disease, for the purpose of this study, is the endstage, progressive disease, not responding to treatment, which is most likely the immediate cause of death or results in such a deterioration of performance status that could make a patient vulnerable to any secondary cause of death.

In Poland, the law requires an autopsy for all patients who have died in hospital, but when there is no doubt regarding the cause of death, the Chief of the Department can evade this requirement upon written request from the patient's family. Routinely, autopsies are bypassed in the case of almost all patients with advanced diseases. Bypassing an autopsy is not permitted in the case of patients dying within $24 \mathrm{~h}$ of admission as it is legally assumed that the hospital did not have enough time to precisely identify the clinical problems of the patient. An autopsy is performed not earlier than $12 \mathrm{~h}$ after death, and in this hospital it is done usually on the next day, except for patients dying on a Friday and Saturday. Their autopsies are performed on a Monday.

A complete autopsy includes a gross examination of the viscera of the cranium, thorax, abdomen and pelvis, and a collection of tissue specimens that are used for subsequent microscopic evaluations, including special immunohistochemistry staining if necessary. Moreover, special attention to the requests of clinicians is given, who may suggest a collection of a larger than routine number of specimens for microscopic analysis from selected locations.

\section{Data analyzed}

The medical documentation was analyzed with attention to the patient's sex, age, hematological diagnosis and its prognosis, treatment given, time from diagnosis, length of the last hospitalization, comorbidities, suggested cause of death, presence of the Aspergillus spp. infection.

In each case, all the clinical data and autopsy records were evaluated by at least 2 physicians. All doubtful autopsy cases were reviewed by a pathologist other than the one who performed a given autopsy.

The patients were assigned to 3 age groups (18-42; $43-62$; $>62$ years). Specific treatment for the disorders of the last period of life, chemotherapy, radiotherapy and bone marrow or peripheral blood stem cell transplantation were also taken into consideration. Time from diagnosis meant the time from precise diagnosis of hematological disease until death. The mode of dying was an indication whether the process of dying was rapid (hemorrhage, myocardial infarction, arrhythmia, pulmonary embolism or septic shock) or prolonged (others). Special attention 
Table 1. Basic data on the evaluated population of hematological patients

\begin{tabular}{|c|c|c|c|c|}
\hline Diagnosis & $\begin{array}{l}\text { Total number } \\
\text { of patients } \\
\text { deceased }\end{array}$ & $\begin{array}{l}\text { Number } \\
\text { of autopsied } \\
\text { patients } \\
(\%)\end{array}$ & $\begin{array}{c}\text { Number of autopsied patients } \\
\text { deceased in the early stage } \\
\text { of primary disease } \\
n(\%)\end{array}$ & $\begin{array}{c}\text { Number of discrepancies } \\
\text { between clinical and autopsy } \\
\text { diagnoses } \\
\mathrm{n}(\%)\end{array}$ \\
\hline Acute myelogenous leukemia (AML) & 269 & $47(30.5)$ & $26(33.8)$ & $12(21.8)$ \\
\hline Chronic myelogenous leukemia (CML) & 90 & $10(6.5)$ & $5(6.5)$ & $1(1.8)$ \\
\hline Other myeloproliferative diseases & 30 & $3(1.9)$ & $2(2.6)$ & $2(3.6)$ \\
\hline Myelodysplastic syndrome (MDS) & 47 & $5(3.2)$ & $4(5.2)$ & $3(5.5)$ \\
\hline Acute lymphoblastic leukemia (ALL) & 79 & $15(9.7)$ & $5(6.5)$ & $7(12.7)$ \\
\hline Non-Hodgkin's lymphoma (NHL) & 217 & $36(23.4)$ & $13(16.9)$ & $12(21.8)$ \\
\hline Hodgkin's disease (HD) & 30 & $6(3.9)$ & $0(0.0)$ & $3(5.5)$ \\
\hline Chronic lymphocytic leukemia (CLL) & 118 & $9(5.8)$ & $5(6.5)$ & $5(9.1)$ \\
\hline Multiple myeloma (MM) & 215 & $13(8.4)$ & $8(10.4)$ & $5(9.1)$ \\
\hline Aplastic anemia (AA) & 24 & $4(2.6)$ & $4(5.2)$ & $3(5.5)$ \\
\hline Other & 60 & $6(3.9)$ & $5(6.5)$ & $2(3.6)$ \\
\hline Total & 1179 & 154 & 77 & 55 \\
\hline
\end{tabular}

Table 2. Goldman's criteria for major class missed diagnosis 17,39

\begin{tabular}{|l|l|}
\hline \multicolumn{1}{|c|}{ Goldman's class } & \\
\hline Class I & Major misdiagnoses that could have direct impact on management \\
& $\begin{array}{c}\text { Major misdiagnoses that would probably not have changed the management because of: } \\
\text { Class II }\end{array}$ \\
& - lack of appropriate therapy \\
& - refusal of further evaluation or treatment \\
\hline
\end{tabular}

was given to the Aspergillus spp. infection because of its known high incidence in hematological patients. ${ }^{13}$

\section{Discordance evaluation}

The most probable immediate cause of death was defined on the basis of an autopsy study and compared with clinical diagnosis. As a result, the clinically suspected cause of death was classified as concordant or discordant with autopsy findings and categorized according to Goldman's criteria (Table 2). ${ }^{5}$ An experienced clinical hematologist reviewed the doubtful cases. Minor misdiagnoses, not contributing to the immediate cause of death, were not considered. The group of 5 patients whose immediate cause of death was not identified even after an autopsy was excluded from further analysis.

The association between the presence of major class discrepancies and the clinical characteristics of the patients was evaluated. The characteristics comprised of the following factors: age (18-42 years; $43-62$ years; $>62$ years), time from the diagnosis of primary hematological disease ( $<1$ month; $>1$ month), stage of primary disease (advanced or early), duration of the last hospitalization ( $<8$ days; $8-30$ days; $>30$ days), mode of dying (rapid, prolonged), treatment with bone marrow transplantation (BMT) or peripheral blood stem cell transplantation (PBSCT), and presence of the Aspergillus spp. infection.

\section{Statistical analysis}

The data was processed using statistical analysis system (SAS) and Microsoft Excel software. Simple proportions were reported with their $95 \%$ confidence intervals (95\% CI). The association between the clinical characteristics and discrepancy rates was analyzed using the $\chi^{2}$ test. A p-value of 0.05 or less was considered to indicate statistical significance.

\section{Results}

The entire group of 154 autopsies consisted of 11 (7.1\%) autopsies performed because patients died within $24 \mathrm{~h}$ of admission, $142(92.2 \%)$ autopsies performed because of sudden or unexplained death, 8 (5.2\%) autopsies performed on patients participating in clinical trials, and 22 (14.3\%) autopsies performed on patients dying after earlier hematopoietic transplantation. Twenty-six (16.9\%) autopsies were performed because of more than 1 reason.

The median time from the diagnosis of primary hematological disease to death was 494 days. Seventy-seven patients (50.0\%; 95\% CI 41.9-58.2\%) died in advanced stages of their diseases. The median length of the last hospitalization was 26.5 days $( \pm 34.9)$. The mode of dying was rapid in 95 patients (61.7\%; 95\% CI 53.5-69.4\%) and did not 
differ significantly between hematological malignancies. Nineteen patients (12.3\%; 95\% CI 7.6-18.6\%) had an active Aspergillus spp. infection at the time of death.

\section{Immediate causes of death}

Clinical diagnoses of death of patients who were forwarded for autopsy evaluation are listed in Table 3. The most frequent diagnoses of the immediate causes of death as determined by the autopsies of the evaluated patients are shown in Table 4. As it can be observed, the most frequent autopsy-identified cause of death was myocardial infarction. In almost each hematological malignancy, myocardial infarction (ischemia) was the most frequent pathological diagnosis of the immediate cause of death (Table 5). Also considering the age groups, myocardial infarction appeared to be the most common cause of death, characterized by a frequency rate increasing with age (Table 6).

Table 3. Clinical diagnoses of the immediate cause of death in hematological patients

\begin{tabular}{|c|c|c|}
\hline Major clinical diagnosis & $n(\%)$ & $\begin{array}{l}\text { Number } \\
\text { of discordant } \\
\text { diagnoses }\end{array}$ \\
\hline CNS bleeding & $15(9.7)$ & 6 \\
\hline Disseminated hematological disease & $15(9.7)$ & 7 \\
\hline Pneumonia (bacterial) & $13(8.4)$ & 1 \\
\hline Septic shock & $12(7.8)$ & 6 \\
\hline Pulmonary embolism & $11(7.1)$ & 4 \\
\hline Respiratory failure (undefined) & $11(7.1)$ & 7 \\
\hline Myocardial infarction (ischemia) & $10(6.5)$ & 2 \\
\hline Pulmonary edema & $2(1.3)$ & 0 \\
\hline Gastrointestinal bleeding & $8(5.2)$ & 2 \\
\hline Infection without septic shock & $8(5.2)$ & 2 \\
\hline Adult respiratory distress syndrome & $6(3.9)$ & 3 \\
\hline DIC & $6(3.9)$ & 0 \\
\hline Pulmonary bleeding & $6(3.9)$ & 2 \\
\hline Cardiopulmonary failure (undefined) & $6(3.9)$ & 5 \\
\hline Cardiac failure (undefined) & $4(2.6)$ & 4 \\
\hline Asystole & $4(2.6)$ & 0 \\
\hline Peritoneal bleeding & $3(1.9)$ & 0 \\
\hline Paralytic ileus & $2(1.3)$ & 1 \\
\hline Hepatic failure & $2(1.3)$ & 1 \\
\hline Intestinal perforation & $1(0.6)$ & 0 \\
\hline Aspergillosis of CNS & $1(0.6)$ & 0 \\
\hline Pulmonary aspergillosis & $1(0.6)$ & 0 \\
\hline Acute renal failure & $1(0.6)$ & 1 \\
\hline Encephalitis & $1(0.6)$ & 1 \\
\hline Undefined & $5(3.2)$ & 0 \\
\hline Total & $154(100)$ & 55 \\
\hline
\end{tabular}

CNS - central nervous system; DIC - disseminated intravascular coagulation; major clinical diagnosis - clinical diagnosis that served to estimate the discordance with autopsy diagnosis.
With regard to the patients with early stages of primary diseases, the most frequent immediate causes of death were myocardial infarction $(15 ; 19.5 \%)$, bacterial pneumonia 9 (11.7\%), and pulmonary embolism (7; 9.1\%).

Considering the etiology, post-mortem diagnoses of the immediate causes of death were assigned to 9 categories (Table 7 ). In 5 patients (3.2\%; 95\% CI 0.4-5.6\%), the exact cause of death was not identified, even after an autopsy.

The most frequent immediate cause of death in $22 \mathrm{pa}-$ tients with prior bone marrow or peripheral blood stem cell transplantation was aspergillosis (27.3\%), mainly in the pulmonary location (4 out of 6 patients).

\section{Discordances between clinical and anatomopathological investigation}

The discordance between clinical and autopsy diagnoses of the immediate cause of death was found in 55 patients (35.7\%; 95\% CI 28.2-42.8\%). The discrepancies were considered class I in 28 cases (18.2\%) and class II in 27 cases (17.5\%). The details of the discordant cases (class I) are displayed in Table 8. Myocardial infarction was the most frequent class I discrepant diagnosis (42.9\%). Pulmonary aspergillosis, myocardial infarction and gastrointestinal bleeding were the most frequently clinically undiagnosed causes of death (Fig. 1). A more precise analysis of patients with myocardial infarction showed that 6 of them (20.7\%) had a previously diagnosed cardiac disease. The remaining 23 patients with myocardial infarction had a $65.2 \%$ discrepancy rate. The major discrepancy in the diagnosis of myocardial infarction regarded patients in whom

Table 4. Autopsy diagnoses of hematological patients

\begin{tabular}{|l|c|}
\multicolumn{1}{|c|}{ Diagnosis } & $\mathrm{n}(\%)$ \\
\hline Myocardial infarction (ischemia) & $29(18.8)$ \\
\hline Pneumonia (bacterial) & $17(11.0)$ \\
\hline CNS bleeding & $11(7.1)$ \\
\hline Disseminated hematological disease & $10(6.5)$ \\
\hline DIC & $10(6.5)$ \\
\hline Pulmonary edema & $9(5.8)$ \\
\hline Pulmonary embolism & $9(5.8)$ \\
\hline Gastrointestinal bleeding & $9(5.8)$ \\
\hline Infection without septic shock & $8(5.2)$ \\
\hline DAD & $7(4.5)$ \\
\hline Septic shock & $7(4.5)$ \\
\hline Pulmonary aspergillosis & $7(4.5)$ \\
\hline Pulmonary bleeding & $5(3.2)$ \\
\hline Peritoneal bleeding & $3(1.9)$ \\
\hline Unknown & $5(3.2)$ \\
\hline Others & $8(5.2)$ \\
\hline
\end{tabular}

CNS - central nervous system; DAD - diffuse alveolar damage; DIC - disseminated intravascular coagulation. 
clinical diagnoses included central nervous system (CNS) hemorrhage $(5 ; 25.0 \%)$, septic shock $(3 ; 15.0 \%)$ and disseminated hematological disease $(3 ; 15.0 \%)$.

There were no significant differences in the discrepancy rate between patients with different primary hematological diseases (Table 1).

The discrepancy rate in patients with the Aspergillus spp. infection was $42.1 \%$; however, in the group with the pulmonary location, it was $71.4 \%$.

No significant association was found between a major class discordant diagnosis and age, diagnosis time and prognosis of hematological disease, duration of the last hospitalization, mode of dying, prior transplantations (BMT or PBSCT), presence of the Aspergillus spp. infection (Table 9).

\section{Discussion}

To the authors' best knowledge, this study concerns the largest series of autopsies of patients with hematological malignancies and aplastic anemia, and the only one that is focused on an actual, immediate cause of death.

The analysis concerned a group of patients with a fully diagnosed hematological disease. All of them were diagnosed, examined and treated in a highly specialized hematological unit, which assures the uniformity of patient care and decreases the risk of misdiagnosis. ${ }^{1,14}$

The study regarded only the patients with the postmortem examination because it seems to be the best tool to verify clinical diagnosis. ${ }^{1,5,8-10,14-16}$

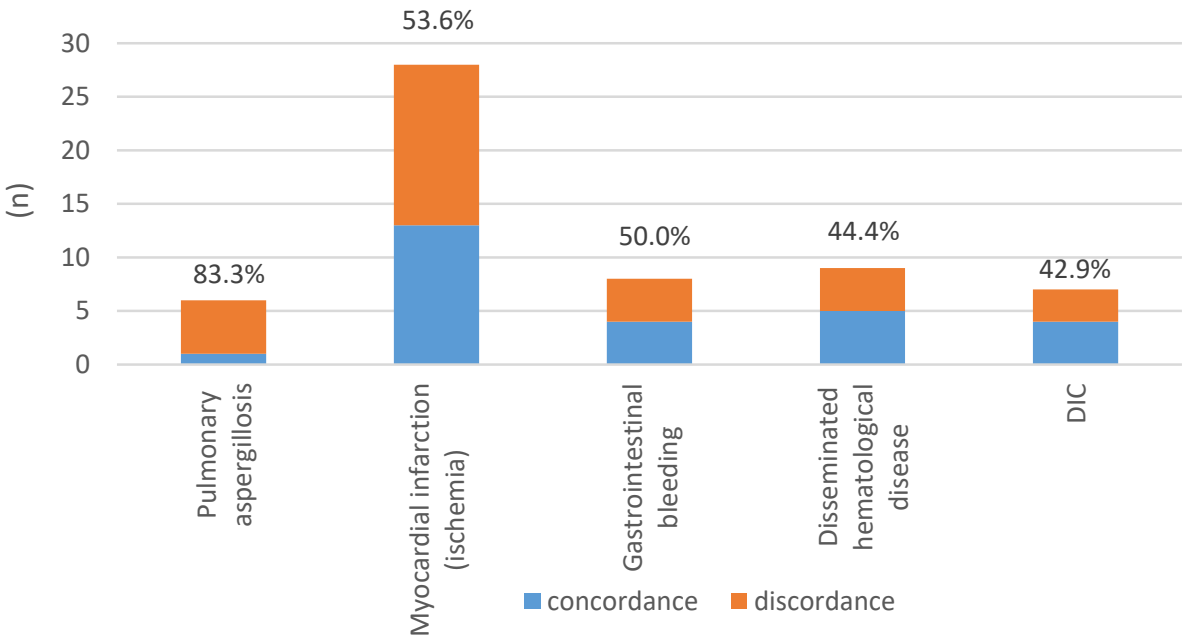

Fig. 1. The percentage of discrepancies between clinical and post-mortem diagnosis of cause of death ( $n=$ number of patients)

Table 5. The most frequent autopsy diagnoses of the immediate cause of death in various blood disorders

\begin{tabular}{|l|c|c|}
\multicolumn{1}{|c|}{ Hematological disease } & The most frequent cause of death & $\mathrm{n}(\%)$ \\
\hline Acute myeloblastic leukemia & myocardial infarction (ischemia) & $9(19.1)$ \\
\hline Non-Hodgkin's lymphoma & myocardial infarction (ischemia) & $8(25.0)$ \\
\hline Multiple myeloma & myocardial infarction (ischemia) or pulmonary embolism & $2(16.7)$ \\
\hline Acute lymphoblastic leukemia & CNS bleeding or respiratory tract bleeding & $2(13.3)$ \\
\hline Chronic myeloid leukemia & pulmonary aspergillosis & $3(33.3)$ \\
\hline Chronic lymphocytic leukemia & myocardial infarction (ischemia) & $3(33.3)$ \\
\hline Hodgkin's lymphoma & myocardial infarction (ischemia) & $2(33.3)$ \\
\hline
\end{tabular}

Table 6. The most frequent causes of death by age

\begin{tabular}{|c|c|c|}
\hline$<43$ years & $43-62$ years & $>62$ years \\
\hline myocardial infarction (ischemia) & myocardial infarction (ischemia) & myocardial infarction (ischemia) \\
$11.5 \%$ & $19.6 \%$ & $25.5 \%$ \\
\hline pneumonia (bacterial) & pulmonary edema & pneumonia (bacterial) \\
$11.5 \%$ & $9.8 \%$ & $13.7 \%$ \\
\hline pulmonary aspergillosis & disseminated hematological disease & gastrointestinal bleeding \\
$7.7 \%$ & $7.8 \%$ & $9.8 \%$ \\
\hline
\end{tabular}


However, the $15.6 \%$ autopsy rate and the limitation to the preselected group of patients may result in the lack of representativeness for the entire population of hematological patients and can lead to an overestimation of discrepancies. On the other hand, the clinical characteristics of the patients including age, sex, underlying hematological disease and its prognosis, length of patient care, length

Table 7. Post-mortem diagnosis assignment to the autopsy categories

\begin{tabular}{|l|c|}
\multicolumn{1}{|c|}{ Autopsy categories } & $\mathrm{n}(\%)$ \\
\hline Infectious & $41(26.6)$ \\
\hline Myocardial infarction (ischemia) & $29(18.8)$ \\
\hline Hemorrhages & $28(18.2)$ \\
\hline Pulmonary edema / DAD & $17(11.0)$ \\
\hline Disseminated neoplastic disease & $10(6.5)$ \\
\hline DIC & $10(6.5)$ \\
\hline Pulmonary embolism & $9(5.8)$ \\
\hline Other & $5(3.2)$ \\
\hline Unknown & $5(3.2)$ \\
\hline
\end{tabular}

of the last hospitalization, suggest that the studied population was very diverse. The differences in the autopsy rate between primary hematological diseases probably result from an acute course of leukemia with a high frequency of death unexplained by the clinical situation of a patient.

The post-mortem study allowed us to identify the immediate cause of death in $96.8 \%$ of cases. Only close collaboration of pathologists and clinicians can make an autopsy study such an effective tool in defining the immediate cause of death. ${ }^{7,14,17}$

Various combined infections were the most frequent causes of death (26.6\% of cases), especially in younger patients ( $<43$ years; $36.5 \%)$. Such data is in accordance with the studies conducted by Goldman et al. (24\%) and Gerrain et al. (23.5\%) in cancer patients, still our values are lower than those reported by Nosari et al. (63\%) in hematological patients, Manci et al.(60\%) in sickle cell disease patients and Provencio et al.(43\%) in patients with Hodgkin's lymphoma. ${ }^{5,7,8,17,18}$ A more detailed analysis of infectious causes of death revealed that bacterial pneumonia, pulmonary aspergillosis and septic shock were the most

Table 8. Patients with class I discrepancy according to Goldman's classification

\begin{tabular}{|c|c|c|c|c|}
\hline Diagnosis & Age (years) & Clinical cause of death & Post-mortem diagnosis & Prognosis \\
\hline PMF & 51 & cardiac failure, undefined & pulmonary embolism & $P$ \\
\hline AA & 54 & respiratory failure & myocardial infarction (ischemia) & $P$ \\
\hline $\mathrm{NHL}$ & 48 & cachexy & pulmonary Aspergillosis & $\mathrm{N}$ \\
\hline CLL & 61 & respiratory failure & myocardial infarction (ischemia) & P \\
\hline CML & 47 & congestive heart failure & pulmonary Aspergillosis & $\mathrm{N}$ \\
\hline AML & 25 & ARDS, gastrointestinal bleeding & pneumonia & $P$ \\
\hline ALL & 18 & CNS bleeding & septic shock & N \\
\hline AML & 36 & cachexy & pulmonary Aspergillosis & $P$ \\
\hline NHL & 46 & gastrointestinal bleeding & myocardial infarction (ischemia) & P \\
\hline AML & 42 & CNS bleeding, intestinal paralysis & myocardial infarction (ischemia) & $\mathrm{N}$ \\
\hline MM & 42 & CNS bleeding & myocardial infarction (ischemia) & P \\
\hline HD & 70 & respiratory failure, septic shock & myocardial infarction (ischemia) & $\mathrm{N}$ \\
\hline HD & 28 & pneumonia, renal failure & disseminated hematological disease & P \\
\hline $\mathrm{CLL}$ & 65 & pneumonia & pulmonary embolism & $P$ \\
\hline AML & 76 & pulmonary embolism & myocardial infarction (ischemia) & $P$ \\
\hline HD & 42 & cachexia & myocardial infarction (ischemia) & $\mathrm{N}$ \\
\hline HD & 28 & respiratory failure, hepatic failure & pulmonary embolism & N \\
\hline PMF & 59 & cachexy & myocarditis & N \\
\hline NHL & 62 & stroke, CNS bleeding & myocardial infarction (ischemia) & $P$ \\
\hline ALL & 67 & respiratory failure (cerebral cause) & myocardial infarction (ischemia) & N \\
\hline AML & 38 & cardiopulmonary failure, pneumonia & gastrointestinal bleeding & N \\
\hline AML & 68 & CNS bleeding & myocardial infarction (ischemia) & $P$ \\
\hline $8 \mathrm{AML}$ & 53 & respiratory failure, undefined cause & pneumonia & P \\
\hline AML & 32 & cachexy & myocardial infarction (ischemia) & N \\
\hline ALL & 39 & septic shock & gastrointestinal bleeding & N \\
\hline NHL & 34 & cachexy & myocardial infarction (ischemia) & $\mathrm{N}$ \\
\hline
\end{tabular}

PMF - primary myelofibrosis; $\mathrm{P}$ - positive prognosis; $\mathrm{N}$ - negative prognosis. 
frequent causes. Additionally, it was found that 24 out of 41 infectious cases (58.5\%) involved the respiratory tract.

The most frequent cause of death, when considering single pathology, was myocardial infarction $(18.8 \%$ of cases). Furthermore, myocardial infarction was observed to be the most frequent immediate cause of death in all age groups ( $<43$ years; $43-62$ years; $>62$ years) and almost in each hematological malignancy. There are many factors that predispose hematological patients to heart failure: age, anemia, cardiotoxicity of chemotherapeutics, overload with fluids, increased body temperature, to name a few. Moreover, some symptoms of cardiac insufficiency may be masked by therapy or other complications, e.g., pain, tachypnea. The major discrepancy in the diagnosis of myocardial infarct considered CNS bleedings. The discrepancy is probably due to the unspecific symptoms that mask heart failure, and the diagnosis of CNS hemorrhage seems to be a safe guess for the doctor. The majority of patients who died of myocardial infarction $(22 / 29 ; 75.9 \%)$ were exposed to chemotherapeutic agents of known cardiotoxicity, usually anthracyclines or radiotherapy. ${ }^{12,19-22,23}$ To the authors' best knowledge, this is the first study reporting myocardial infarction as the most frequent cause of death.

The underlying hematological disease was found to be the immediate cause of death in 10 patients (6.5\%). Such an observation differs from that reported by Provencio et al. in patients with Hodgkin's lymphoma (37\%), but is similar to the observation of Gerrain et al. in cancer patients $(11.8 \%)^{7,8}$

The discordance rate between clinical and post-mortem diagnoses of the immediate cause of death was $35.7 \%$.

Table 9. Occurrence of discrepancy per clinical characteristic

\begin{tabular}{|c|c|c|c|}
\hline Factor & $\begin{array}{c}\text { Number of } \\
\text { patients }\end{array}$ & $\begin{array}{c}\text { Number of } \\
\text { discrepancies } \\
n(\%)\end{array}$ & $p$-value \\
\hline $\begin{array}{l}\text { Age (years) } \\
18-42 \\
43-62 \\
>64\end{array}$ & $\begin{array}{l}44 \\
42 \\
43\end{array}$ & $\begin{array}{l}19(43.2) \\
14(33.3) \\
13(30.2)\end{array}$ & $\begin{array}{l}0.47 \\
0.94\end{array}$ \\
\hline $\begin{array}{l}\text { Prognosis } \\
\text { negative } \\
\text { positive }\end{array}$ & $\begin{array}{l}60 \\
69\end{array}$ & $\begin{array}{l}27(45.0) \\
19(27.5)\end{array}$ & 0.06 \\
\hline $\begin{array}{l}\text { Time of hospitalization } \\
\leq 7 \text { days } \\
8-30 \text { days } \\
>30 \text { days }\end{array}$ & $\begin{array}{l}30 \\
65 \\
34\end{array}$ & $\begin{array}{c}9(30.0) \\
24(36.9) \\
13(38.2)\end{array}$ & $\begin{array}{l}0.60 \\
0.91 \\
0.88\end{array}$ \\
\hline $\begin{array}{l}\text { Diagnosis } \\
\text { of hematological disease } \\
<1 \text { month } \\
>1 \text { month } \\
<8 \text { months } \\
\geq 8 \text { months }\end{array}$ & $\begin{array}{c}25 \\
100 \\
63 \\
62\end{array}$ & $\begin{array}{c}6(24.0) \\
40(40.0) \\
22(34.9) \\
24(38.7)\end{array}$ & $\begin{array}{l}0.21 \\
0.80\end{array}$ \\
\hline Transplantation & 19 & $8(42.1)$ & 0.77 \\
\hline Aspergillosis & 14 & $6(42.9)$ & 0.82 \\
\hline Rapid death & 79 & $22(27.9)$ & 0.03 \\
\hline Long-term death & 50 & $24(48.0)$ & \\
\hline
\end{tabular}

This may seem high, but an autopsy was ordered primarily in cases where clinical diagnosis was doubtful or the cause of death was at least partially unexplained to the ordering physician. Previously conducted studies in hematological and oncological units showed a higher incidence of discrepancies. ${ }^{7,8}$ A systematic review performed by Shojania et al., who evaluated 53 studies of autopsy series concerning patients with various disorders, other than hematological, revealed a range of major errors from $4.1 \%$ to $49.8 \%{ }^{11}$ Our data is within these limits.

In this study, management would have been modified (class I discrepancies) in $18.2 \%$ of cases. It is apparently more frequently than in other studies of patients without neoplasia but less frequently than in the studies of oncological patients. ${ }^{1,5,7,11,23,24}$ A higher rate of class I discrepancies reported by Xavier et al. in hematological patients (31.3\%) may be due to the treatment in an unspecialized unit. ${ }^{14}$ All the data might confirm that a highly complex course of malignant disorders might result from the elevated rates of discrepancies. The evaluation of the prognosis was performed in order to assess if the modification of management in class-I-discrepant patients could have influenced the survival. It was shown that $39.3 \%$ of class-I-discrepant patients were in the early stages of their primary diseases. This may suggest that an appropriate modification of management focused on early diagnosis and treatment of heart infarct may decrease the mortality rate.

An unexpected and previously not reported observation was that myocardial infarct or extensive myocardial ischemia was undiagnosed in $69 \%$ of cases. The clinically suspected causes of death in these patients were hemorrhages, especially cerebral, septic shock and disseminated hematological disease. This suggests more intensive attention to the cardiac problems in hematological patients.

Infection was misdiagnosed in 18 out of 41 cases (43.9\%). This finding is in accordance with various studies. . $^{5,16,25,26}$ However, the number of undiagnosed infections in some studies is higher. ${ }^{18,27}$ A more detailed analysis showed that $42.1 \%$ of the Aspergillus spp. infections and $71.4 \%$ of pulmonary aspergillosis were overlooked. Donhuijsen et al. reported a high and increasing incidence of mycoses in hematological patients, which positively correlates with the present study. ${ }^{13}$ As previously suggested by other authors, infectious processes are likely to remain undetected and their symptoms can mimic tumor progression.

Pulmonary embolism was observed as the most frequent missed diagnosis in various studies. ${ }^{7,25,28}$ This was not confirmed by our study (33.3\% of discrepant cases). The difference may result from the limitation of our group to hematological patients and previously reported decreasing incidence of misdiagnosed pulmonary embolism. ${ }^{5}$

Xavier et al. reported hematological disease to be the most commonly discordant diagnosis in hematological patients. ${ }^{14}$ The present study was performed in a specialized hematological unit, which probably limited the rate of misdiagnoses. 
Another purpose of this study was to assess the occurrence of discrepancies in accordance with clinical characteristics. No clinical feature showed a statistically significant relation to major or class I discrepancies. Underrepresented studies regarding the association of a clinical characteristic with major class discrepancies reported various data, of which only care in a specialized unit was independently and inversely related to the occurrence of class I discrepancy. ${ }^{2,14,29,30}$ In the present study, all the patients were hospitalized in a specialized unit, which excludes the possibility of such a relation.

The underlying hematological disease by itself rarely leads to death, while the complications of therapy and specific disorders appearing in its course in the majority of cases are responsible for the patient's death. An autopsy study together with a clinical investigation providing the information about the immediate cause of death focus the attention of clinical physicians on frequently misdiagnosed, life-threatening pathologies. It seems essential to perform comprehensive analyses of the results of post-mortem examinations to make the autopsy findings available to a wider group of physicians in charge of the patients, which might result in a decrease of discrepancies in the future.

\section{Conclusions}

This data suggests that hematological patients require special attention and preventive measures concerning coronary heart disease, particularly during the initiation of antineoplastic therapy.

\section{References}

1. Avgerinos DV, Bjornsson J. Malignant neoplasms: Discordance between clinical diagnoses and autopsy findings in 3,118 cases. APMIS. 2001;109:774-780.

2. Tavora F, Crowder CD, Sun CC, Burke AP. Discrepancies between clinical and autopsy diagnoses: A comparison of university, community, and private autopsy practices. Am J Clin Pathol. 2008;129(1):102-109.

3. Ayoub T, Chow J. The conventional autopsy in modern medicine. $J$ R Soc Med. 2008;101(4):177-181.

4. Burton EC, Troxclair DA, Newman WP ${ }^{\text {rd }}$. Autopsy diagnoses of malignant neoplasms: How often are clinical diagnoses incorrect? JAMA. 1998;280:1245-1248.

5. Goldman L, Sayson R, Robbins S, Cohn LH, Bettmann M, Weisberg M. The value of the autopsy in three medical eras. NEng/J Med. 1983;308:1000-1005.

6. Sinard JH. Factors affecting autopsy rates, autopsy request rates, and autopsy findings at a large academic medical center. Exp Mol Pathol. 2001;70(3):333-343.

7. Gerain J, Sculier JP, Malengreaux A, Rykaert C, Themelin L. Causes of deaths in an oncologic intensive care unit: A clinical and pathological study of 34 autopsies. Eur J Cancer. 1990;26:377-381.

8. Provencio M, Espana P, Salas C, Navarro F, Bonilla F. Hodgkin's disease: Correlation between causes of death at autopsy and clinical diagnosis. Ann Oncol. 2000;11;59-64.

9. Singh $\mathrm{H}$, Sethi S, Raber M, Petersen LA. Errors in cancer diagnosis: Current understanding and future directions.J Clin Oncol. 2007;25(31):5009-5018.

10. Pritt BS, Hardin NJ, Richmond JA, Shapiro SL. Death certification errors at an academic institution. Arch Pathol Lab Med. 2005;129(11):1476-1479.

11. Shojania KG, Burton EC, McDonald KM, Goldman L. Changes in rates of autopsy-detected diagnostic errors over time: A systematic review. JAMA. 2003;289:2849-2856.
12. Soracci R. Autopsy as the yardstick for diagnosis: An epidemiologist's remark. IARC Sci Publ. 1991;(112):185-196.

13. Donhuijsen K, Pfaffenbach B, Samandari S, Leder LD. Autopsy results of deep mycoses in hematologic neoplasms (1053 patients). Mycoses. 1991;34(Suppl1):25-27.

14. Xavier ACG, Siqueira SAC, Costa LJM, Mauad T, Nascimento Saldiva PH. Missed diagnosis in hematological patients: An autopsy study. Virchows Arch. 2004;446:225-31.

15. Saviola A, Luppi M, Potenza L, et al. Myocardial ischemia in a patient with acute lymphoblastic leukemia during L-asparaginase therapy. Eur J Haematol. 2004;72(1):71-72.

16. Tai DYH, El-Bilbeisi H, Tewari S, Mascha EJ, Wiedemann HP, Arroliga AC. A study of consecutive autopsies in a medical ICU. Chest. 2001;119:530-536.

17. Manci AE, Culberson DE, Yih-Ming Yang, et al. Causes of death in sickle cell disease: An autopsy study. BJH. 2003;123:359-365.

18. Nosari A, Barberis $M$, Landonio $G$, et al. Infections in haematologic neoplasms: Autopsy findings. Haematologica. 1991;76(2):135-140.

19. Assiri AH, Lamba M, Veinot JP. Chronic lymphocytic leukemia involving the coronary arteries with accompanying acute myocardial infarction. Cardiovasc Pathol. 2005;14(6):324-326.

20. López-Miranda V, Herradón E, González C, Martín MI. Vascular toxicity of chemotherapeutic agents. Curr Vasc Pharmacol. 2010;8(5):692-700.

21. Plana JC, Galderisi M, Barac A, et al. Expert consensus for multimodality imaging evaluation of adult patients during and after cancer therapy: A report from the American Society of Echocardiography and the European Association of Cardiovascular Imaging. Eur Heart J Cardiovasc Imaging. 2014;15(10):1063-1093.

22. Volkova M, Russell R. Anthracycline cardiotoxicity: Prevalence, pathogenesis and treatment. Curr Cardiol Rev. 2011;7(4):214-220.

23. Kuijpers CC, Fronczek J, van de Goot FR, Niessen HW, van Diest PJ, Jiwa M. The value of autopsies in the era of high-tech medicine: Discrepant findings persist. J Clin Pathol. 2014;67(6):512-519.

24. Ioan B, Alexa T, Alexa ID. Do we still need the autopsy? Clinical diagnosis versus autopsy diagnosis. Rom J Leg Med. 2012;20:307-312.

25. Maris C, Martin B, Creteur J, et al. Comparison of clinical and postmortem findings in intensive care unit patients. Virchows Arch. 2007;450(3):329-333.

26. Stevanovic G, Tucakovic G, Dotlic R, Kanjuh V. Correlation of clinical diagnoses with autopsy findings: A retrospective study of 2,145 consecutive autopsies. Hum Pathol. 1986;17(12):1225-1230.

27. Hofmeister CC, Marinier DE, Czerlanis C, Stiff PJ. Clinical utility of autopsy after hematopoietic stem cell transplantation. Biol Blood Marrow Transplant. 2007;13(1):26-30.

28. Spiliopoulou C, Papadodima S, Kotakidis N, Koutselinis A. Clinical diagnoses and autopsy findings: A retrospective analysis of 252 cases in Greece. Arch Pathol Lab Med. 2005;129(2):210-214.

29. Dimopoulos G, Piagnerelli M, Berré J, Salmon I, Vincent JL. Post mortem examination in the intensive care unit: Still useful? Intensive Care Med. 2004;30(11):2080-2085.

30. Perkins GD, McAuley DF, Davies S, Gao F. Discrepancies between clinical and postmortem diagnoses in critically ill patients: An observational study. Crit Care. 2003;7:R129-R132. 